\title{
Por uma antropologia de varanda reversa: etnografando um encontro entre índios e crianças em uma escola no Rio de Janeiro ${ }^{1}$
}

Guilherme Fians

University of Manchester, Manchester, Reino Unido

DOI 10.11606/issn.2316-9133.v24i24p202-222

resumo Este trabalho se baseia na etnografia de um encontro entre crianças em uma escola no Rio de Janeiro e dois ex-moradores da Aldeia Maracanã. Um dos pontos centrais da proposta pedagógica dessa escola em questão é a "valorização da cultura brasileira", levando em consideração suas diversas manifestaçôes e invocando principalmente elementos de culturas indígenas. Como parte desse projeto, uma das iniciativas tomadas pela escola foi convidar dois defensores da causa indígena para "apresentarem seu povo e sua cultura" para as crianças do segundo ano do ensino fundamental. Minha intenção neste artigo é explorar as aproximaçóes, os afastamentos e os questionamentos gerados durante esse contato - no qual, tal como em uma antropologia de varanda, os índios vêm até o meio dos brancos para explicar sua cultura.

palavras-chave Criança; Escola; Teoria antropológica; Antropologia de varanda; Povos indígenas.

For a reversed "verandah anthropology": ethnographying an encounter between indigenous peoples and children in a school in Rio de Janeiro

abstract This work is based on the ethnography of an encounter between children in a school in Rio de Janeiro and two former residents of Aldeia Maracaná. One of the key points of this school's pedagogical proposal is the "valorisation of the Brazilian culture", taking into consideration its diverse manifestations and especially invoking elements of indigenous cultures. As part of this project, one of the school's initiative was to invite two defenders of the indigenous cause to "present their people and their culture" to the children from the second grade of elementary school. This article aims to explore the approximations, distances and questionings provoked in this contact - in which, as in verandah anthropology, the indigenous peoples come to the whites to explain their culture.

keywords Children; School; Anthropological theory; Verandah anthropology; Indigenous peoples. 
Bronislaw Malinowski (1976) é frequentemente reconhecido como sendo o sistematizador da observação participante, a moderna técnica de pesquisa de campo na antropologia. Por meio dela, os antropólogos se propóem a acompanhar de perto o cotidiano dos grupos, sociedades e culturas estudadas - em outras palavras, "aprender o ponto de vista dos nativos, seu relacionamento com a vida, sua visão de seu mundo" (MALINOWSKI, 1976, p. 33-34) -, vivenciando parte dessas práticas e costumes e registrando as informaçóes coletadas nessa pesquisa em um caderno de campo. Essas anotaçôes posteriormente virão a ser condensadas e trabalhadas de modo a virem a constituir uma etnografia, a qual consiste em uma exposição dos resultados do trabalho de campo e em um tratamento das observações obtidas.

Em períodos anteriores, a técnica de pesquisa predominante, que precedeu o trabalho de campo por observação participante, consistia em coletar informações sobre a organização social e o sistema de valores dos povos nativos por meio de um diálogo com alguns dos membros de uma aldeia ou grupo. Como esse encontro se dava fora do local habitado pelos nativos - frequentemente na área externa de postos indígenas ou de casas da região onde se realizava a pesquisa -, esse procedimento ficou conhecido a posteriori como antropologia de varanda. ${ }^{2}$ As perguntas feitas a esses informantes, assim como os relatos elaborados por eles, eram usados como fonte de informaçóes para se reconstituir a vida nativa, de modo que a ida do antropólogo ao campo se tornava dispensável.

$\mathrm{O}$ fato de esse método não ser mais costumeiramente usado por antropólogos, no entanto, não significa que ele tenha sido completamente invalidado como uma forma de se acessar conhecimentos sobre povos indígenas. Para crianças de uma escola no Rio de Janeiro, por exemplo, ele foi uma forma interativa e lúdica de pôr em diálogo dois defensores da causa indígena com uma turma de alunos do segundo ano do ensino fundamental. No entanto, até que ponto se pode aprender sobre índios trazendo-os para a sala de aula - a nova varanda?

Neste artigo, pretendo narrar o encontro desses representantes indígenas com os alunos da referida turma de uma escola. Para isso, busco mapear algumas das controvérsias suscitadas durante o debate entre eles, explorando as aproximaçóes e afastamentos gerados durante esse encontro - no qual, tal como em uma antropologia de varanda, os índios vêm até o meio dos brancos para explicar seu povo e sua cultura. Ao mesmo tempo que esse contato promove uma identificação, também estimula questóes relativas à humanidade do índio, identidade, pertencimento e diferença, em um espaço no qual a pergunta central posta pelas crianças é: "Quem são esses índios?”. 


\section{Turmas, etnias e turmas-etnias}

O encontro entre indígenas e crianças que narro neste artigo foi presenciado por mim durante meu trabalho de campo, realizado entre fevereiro e maio de 2014, na Escola Oga Mitá, uma instituição de ensino privada localizada no bairro de Vila Isabel, na Zona Norte da cidade do Rio de Janeiro. ${ }^{3}$ Os estudantes dessa escola são, em geral, de famílias das chamadas classes médias, residentes majoritariamente nos bairros de Vila Isabel, Tijuca, Maracaná, Andaraí e Grajaú. A escola tem duas unidades, sendo que uma - na qual realizei a pesquisa - contempla turmas da educação infantil e do primeiro segmento do ensino fundamental.

Um dos pontos centrais da proposta pedagógica dessa escola é a "valorização da cultura brasileira", levando em consideração suas diversas manifestaçóes e invocando principalmente elementos de culturas indígenas. Para isso, um de seus objetivos é buscar uma aproximação entre alguns elementos da educação escolar formal com a educação indígena. Nesse sentido, o website da instituiçáo informa, em relação à origem do nome da escola: ${ }^{4}$

A escola foi criada em 1978, com crianças da Educação Infantil, numa época em que a maioria das escolas tinha nomes estrangeiros, ou os famosos Tia Fulana e nomes no diminutivo. Como nosso projeto era valorizar a história do nosso país, o respeito às diferenças étnicas, de gênero, de valores e socioculturais, optamos por um nome que traduzisse a brasilidade e nossas raízes indígenas: Oga Mitá, uma adaptação do tupi-guarani que significa "casa da criança”.

Essa proposta também guarda traços em comum com as sugestóes de reconhecimento e valorização da diversidade cultural registradas nos Parâmetros Curriculares Nacionais (PCNs):

Tratar da presença indígena, desde tempos imemoriais em território nacional, é valorizar sua presença e reafirmar seus direitos como povos nativos, como tratado na Constituição de 1988. É preciso explicitar sua ampla e variada diversidade, de forma a corrigir uma visão deturpada que homogeneíza as sociedades indígenas como se fossem de um único grupo, pela justaposição aleatória de traços retirados de diversas etnias. Nesse sentido, a valorizaçáo dos povos indígenas faz-se tanto pela via da inclusão nos currículos de conteúdos que infor- 
mem sobre a riqueza de suas culturas e a influência delas sobre a sociedade como um todo, quanto pela consolidação das escolas indígenas que destacam, nos termos da Constituição, a pedagogia que lhes é própria (MEC, 1997, p. 31).

Como parte do mesmo projeto, as turmas da escola, em vez de receberem nomenclaturas numéricas - como turmas 101, 102, 201 etc. -, têm nomes de grupos indígenas, entre os quais, no ano em que fiz a pesquisa, se encontravam: Fulni-ô, Ashaninka, Mynky, Kaimbé, entre outros. De um ano para o outro, o nome da turma a acompanha, até que os alunos daquela turma se formem e sejam permanentemente reconhecidos pelos alunos e ex-alunos da escola como "Ashaninkas", "Kaimbés", entre outros.

Essa analogia entre educação indígena e educação escolar formal deriva da proposta político-pedagógica da escola, de aproximar sua pedagogia daquela apresentada como sendo mais parecida com as praticadas pelos índios nas aldeias na orientação de seus filhos e descendentes. Embora a escola não abandone os preceitos e exigências da Lei de Diretrizes e Bases da Educação (a LDB, de 1996), ela busca promover algumas pequenas alteraçóes que a aproximem do que eles chamam de "cultura indígena" - como, por exemplo, organizando um ritual de passagem de turma entre professores de um ano ao outro, realizando um evento anual de trocas de conhecimentos entre turmas chamado Moitará (em alusão a um ritual de trocas entre grupos indígenas do Alto Xingu), além de promover projetos que estimulem os estudantes a pesquisar questóes como: quem são os índios da etnia que dá nome à sua turma? O que significa ser dessa etnia? De modo análogo, o que significa ser dessa turma e parte desse grupo? E o que significa ser criança nessa etnia e nessa turma?

Como parte dessa busca para promover a "brasilidade" e o conhecimento sobre povos indígenas, algumas professoras da escola, com o apoio da coordenação, convidaram dois membros atuantes na defesa das causas indígenas para conversarem com as crianças das turmas do segundo ano do ensino fundamental, as quais têm idades entre seis e sete anos. Esse encontro foi promovido no dia 13 de março de 2014, uma quinta-feira, com uma turma do turno da manhã e uma do turno da tarde. ${ }^{5}$ Antes disso, no entanto, essa possibilidade foi debatida com os responsáveis pelas crianças da turma, em uma reunião que envolveu pais e demais familiares, professores e coordenadores, no dia 24 de fevereiro de 2014, uma segunda-feira.

Ao acompanhar, narrar e pensar as aproximações e afastamentos entre pais, professores, coordenadores, crianças e índios, parto aqui das questóes que foram suscitadas pelos próprios atores, quais sejam: Quem são esses índios? O que é ser índio? Quem é e quem não é índio? Como eles vivem? 
E ainda: $\mathrm{O}$ que os diferencia de nós? Para isso, começo tratando do primeiro encontro, no qual os pais se veem diante da possibilidade do contato de seus filhos com os índios.

\section{Pais, um antropólogo e dois indígenas na escola}

Por volta das dezoito horas, após o término da aula da turma de segundo ano do ensino fundamental, a sala de aula se tornou o espaço onde pais, responsáveis, professora e coordenadora se reuniriam. Esse encontro de pais e professores ocorre regularmente, e este, especificamente, como primeiro do ano, tinha como principal objetivo apresentar às famílias os projetos da escola a serem realizados ao longo do ano letivo, além de ouvirem dos pais o que eles tinham a dizer sobre esse planejamento anual.

Um dos temas a serem abordados com a turma girava em torno de questóes sobre pessoalidade e individualidade, com a finalidade de que as crianças se percebessem enquanto indivíduos, lidando com sua identificaçáo, certidóes de nascimento, fotos e autorretratos, nomes e sobrenomes. O objetivo seguinte seria debater a relação de cada criança com a turma, discutindo essa identidade coletiva. Como as turmas têm nomes de etnias indígenas, a questão se colocava de uma forma mais ampla e comparativa: "Quem sáo os Manchineri?"' - pergunta que se referia tanto à turma da escola quanto à etnia indígena de mesmo nome.

Para promover o debate sobre povos indígenas e fazer o contraponto entre as crianças indígenas e os alunos, uma professora de outra turma havia sugerido à escola convidar algum indígena para ir até lá. Acolhendo a sugestão, a coordenadora Manuela e a professora Tatiane conversaram com as famílias, durante a reunião, sobre a possibilidade de chamarem um índio "para falar sobre seu povo e seus costumes para a turma".

Manuela estava se referindo a Awá Tembé e a Moisés Lopes, ambos militantes do movimento indígena e ex-moradores da Aldeia Maracaná, localizada no prédio do antigo Museu do Índio, ao lado do Estádio do Maracaná, na cidade do Rio de Janeiro. Enquanto Awá Tembé é um indígena que nasceu e morou em uma aldeia no interior do Maranhão, Moisés Lopes é um jornalista carioca - ex-aluno de uma das primeiras turmas da Escola Oga Mitá - que, indo viver entre os índios, passou a se identificar com eles e a defender a causa indígena. Ao se referir a Moisés, a coordenadora Manuela falou aos pais na reuniāo: "O que é interessante nele também é que ele é um branco, não índio, que se tornou índio. Antes ele não era índio, era como... gente [falou, apontando para o próprio corpo] que se transformou em índio". A fala de Manuela foi complementada pela da professora Tatiane: "É, ele se tornou índio, passou a ter também um nome indígena e a viver com os índios". 
A intenção de ambas, ao ressaltarem esses aspectos, era a de sugerir que esse encontro levaria as crianças a pensar em mais questóes sobre identidade - o que, no caso, inclui uma troca de identidade, de não índio a índio.

Ao falarem sobre o índio, o não índio e a possibilidade de se passar de uma identidade a outra, alguns pais presentes na reuniáo também fizeram comentários. Alberto, pai de Paulo, disse:

Foi interessante falar nisso porque hoje de manhã o Paulo foi comigo no posto de saúde para a gente vacinar a irmázinha dele, e lá tinha um cartaz com uma imagem de várias crianças que iam ser vacinadas, e uma delas era um índio. Aí ele me perguntou: "Pai, mas índio também precisa tomar vacina?", e eu respondi: "É, filho, antigamente eles não precisavam, mas depois teve o contato com os brancos, aí começaram a aparecer várias doenças, e aí eles tiveram que começar a tomar”.

A maioria dos presentes sorriu, e logo depois Juliana, mãe de Letícia, também comentou sobre os índios no mundo dos brancos:

Inclusive, uma coisa muito legal que está acontecendo agora é que um índio Ava-Ka... Ava... ["Canoeiro?" - sugeriu Manuela]. Não, acho que é Kaiowá... defendeu uma tese essa semana lá no Museu Nacional, na Antropologia Social, e se tornou o primeiro índio brasileiro com diploma de doutorado em Antropologia!

Em seguida, Nilda, mãe de Larissa, complementou: "O Museu Nacional também seria um bom lugar para um passeio com as crianças, porque tem bastante coisa sobre índios lá”.

Como essa foi a primeira reunião de pais e professores no ano, eu havia pedido a Tatiane para que eu também pudesse me apresentar aos pais, de modo a informá-los sobre o trabalho de campo que eu pretendia fazer naquela turma, e para posteriormente pedir que eles assinassem os termos de consentimento, formalizando essa permissáo. Assim, aproveitando a menção ao Museu Nacional, Tatiane disse: "Falando nisso, o Guilherme é antropólogo! Vou até pedir para ele falar um pouquinho sobre isso para vocês!".

Rapidamente, a atenção dos pais se voltou dos índios para aquele que, a princípio, estuda índios. ${ }^{8}$ Aproveitei esse momento para me apresentar e explicar um pouco da minha pesquisa, justificando o meu interesse por estudar uma turma naquela faixa etária e pedindo a permissão deles. Julia- 
na, mãe de Letícia, concordou, exclamando: "Um antropólogo na [turma] Manchineri! Está no lugar certo!"' e, quando eu disse que passava a manhã e a tarde na escola, acompanhando uma turma de cada turno, ela complementou: "Puxa, você vê tanta criança que, de noite, quando você vai dormir, em vez de contar carneirinhos, você conta crianças!".

Voltando aos debates sobre os conteúdos e temas a serem abordados pela turma, todos concordaram em convidar os dois indígenas - ou "o índio" e "o jornalista carioca que virou índio" - para visitarem a turma. Esse encontro viria a ser marcado para algumas semanas depois da reunião, de forma que a professora e as crianças já tivessem avançado algumas das discussões sobre os tópicos que envolviam a turma e as crianças, a etnia e os indígenas.

\section{Aproximações e afastamentos}

Assim que os alunos da turma Manchineri, do segundo ano do ensino fundamental, começaram a entrar na sala e a colocar suas mochilas no lugar que lhes é reservado, a professora Tatiane chamou todos para se sentarem em roda no chão da sala. Quando a maioria das doze crianças da turma havia chegado, Tatiane disse:

- Hoje eu tenho uma surpresa para vocês. Hoje vem um índio aqui para visitar a nossa turma, e a gente vai entrevistar ele!

- A gente vai receber a visita de um índio? - perguntou Bruno, animado.

- A gente já viu um índio de verdade! - disse Thiago.

-É, a gente já viu um índio. Ele veio aqui no ano passado... - reclamou Letícia.

Enquanto Tatiane sugeria que as crianças pensassem possíveis questóes a serem perguntadas aos visitantes, Alexandre gritou, enquanto pulava, batendo a palma da mão na boca de forma ritmada: "Peraí, gente, acho que eu ouvi um barulho de índio! Uh! Uh! Uh! Uh!”.

Antes da chegada dos visitantes, as crianças formulavam perguntas a serem feitas a eles. Essas discussóes, que vão de um relativismo cultural a uma espécie de relativismo natural - o qual, como discuto adiante, inclui ainda um questionamento de aspectos da humanidade do índio - é o que parece ser o mais interessante a ser abordado por um estudo antropológico.

Como Tatiane tentava focar a discussão em questôes sobre identidade, as primeiras perguntas giraram em torno de certidóes de nascimento, até que Paulo perguntou para Tatiane e para o restante da turma:

- Se as crianças indígenas náo nascem em hospitais, entấo onde elas nascem? 
- As pessoas que saem da barriga da máe fora do hospital nascem e ficam pequenininhas! - Thiago imediatamente respondeu, buscando participar.

- Mas por que você está dizendo isso? - perguntou Tatiane.

- Porque eu tenho uma empregada, que se chama Fátima, que teve uma filha que nasceu assim e ficou pequenininha!

- Ah, Thiago, mas é porque às vezes ela pode ter tido uma complicação, e ter ficado assim por causa disso - disse Tatiane, tentando corrigi-lo.

- Eu sei onde é a maternidade do índio! É o rio! Porque eles nascem na água, porque tem água na barriga da mãe, e no rio eles já nascem nadando - disse Paulo, retomando a questáo anterior.

O tópico seguinte foi sobre como os índios se deslocam até suas escolas. Paulo buscou responder: "Ah, eles andam a pé, a cavalo, de girafa, de búfalo!". Fernando discordou, dizendo: "Mas não tem girafa aqui! Só no zoológico, e na África!", ao que Paulo replicou: "Mas também tem índio na África!".

Nesse momento, os dois visitantes chegaram à porta da sala, esperando o convite da professora para entrarem. Entre o anúncio da visita e a chegada dos indígenas, Tatiane informou às crianças: "Vão vir duas pessoas aqui. Um, eu acho que é índio, que nasceu na tribo mesmo. O outro nasceu aqui, mas foi viver na tribo com os índios". Rapidamente, as crianças começaram a discutir entre si outras perguntas a serem feitas: "Como é o vaso sanitário deles?", "Como é o casamento dos índios?", "Eles têm lua de mel?".

Nesse momento, a coordenadora Manuela e os dois convidados entraram na sala. Awá Tembé usava calça comprida, camisa e sandálias, além de colares, pulseiras e uma bolsa de fabricação indígena e um cocar, enquanto Moisés Lopes estava de bermuda, camisa e tênis, usando apenas um colar, também de fabricação indígena, e sem outros adereços complementares. Awá trouxe ainda outros objetos a serem mostrados para as crianças.

Ambos desejaram uma "Boa tarde!" à turma, e Moisés Lopes se sentou na roda, enquanto Awá Tembé escrevia algumas palavras em Tupi-Guarani no quadro. Ao se juntar aos demais na roda, ele traduziu o que escreveu para o português, explicando que se tratava da forma de ele se apresentar, com seu nome e etnia. Após o final dessa primeira explicação, Letícia levantou a mão e perguntou: "Qual de vocês é o índio do campo e qual é o da cidade?". Awá sorriu e disse: "Eu sou o do interior do Maranhão".

Awá Tembé começou a falar um pouco sobre "seu povo e sua cultura", explicando a localização de sua aldeia no interior do Maranháo e falando sobre seus primeiros anos de vida: o início de sua formaçáo escolar se deu em sua cidade natal, e, em sua escola, o estimularam a esquecer sua língua 
nativa, mas sem convencê-lo disso. Hoje, ele fala tupi-guarani, e usa o português como segunda língua. Disse ainda que, "no seu povo", não existe adolescência e juventude: passa-se diretamente da fase de criança para a vida adulta, na qual todos já podem se casar, embora nem todos o façam imediatamente.

Nesse momento, as crianças começaram a fazer as primeiras perguntas: "Como é o casamento de vocês?"; "Como é o berçário de vocês, quando vocês eram bebês?"; "Como é a cama?". ${ }^{10}$ A essa última pergunta, Awá respondeu: "Tembé não tem cama. Eu já dormi em cama, aqui quando eu fico na cidade, mas lá a gente dorme em rede". A pergunta seguinte - e sua resposta - gerou ainda mais entusiasmo na turma:

- O que vocês comem? Vocês comem inseto e lesma?

- Os Tembé só comem determinado tipo de larva. A gente é muito seletivo nesse sentido. Veja bem, a gente não come gato, não come cachorro, não come felinos... - respondeu Awá.

- É porque vocês já são civilizados, né? - interveio Paulo, querendo participar do diálogo.

- É, a gente ainda vive muito à base de caça, né? - respondeu Awá, com um leve sorriso, possivelmente pensando sobre qual seria essa definiçáo de "civilização".

Por meio da retomada da oposição entre primitivos e civilizados, a busca de similaridades entre "as crianças da aldeia" e "as crianças da cidade" foi progressivamente se convertendo em uma busca pela diferença, por meio de diversas perguntas que passaram a esboçar definiçóes do que os índios são a partir do que eles não são. Nesse sentido, algumas perguntas que se seguiram foram: "Lá tem shopping?"; "Tem loja?"; "Lá tem circo?”; “Tem teatro?”; "Na aldeia tem carro?”; “Tem televisão?”. Awá, então, respondeu que, nos seus tempos de infância, não havia luz na aldeia, e perguntou: "Quem aqui já viu um lampiáo?" Paulo levantou a mão, dizendo "Lampião é um negócio que tem luz, e muitas vezes também é nome de pessoa!". Rindo, Awá respondeu: "Mas aí é o Lampiáo cangaceiro, que já é outra coisa".

Nas palavras de Pierre Clastres, as crianças começaram a formular uma imagem dos índios como sendo determinados "na negativa, sob as marcas da carência" (1979, p. 184), como aqueles que não têm shopping, nem loja, nem circo, nem teatro etc. - como náo possuindo alguns dos elementos comumente presentes nas vidas das crianças na cidade. Como apresentado por Clastres (1979, Capítulo 11), a ausência do Estado e do mercado aparecia constantemente nos relatos de viajantes e exploradores como caracterizadores do "primitivismo" das sociedades indígenas; e, agora, algumas dessas ausências e privações voltam à discussão, na sala de aula, como 
marcadores de diferenças entre as crianças da escola e seus visitantes, entre a vida na cidade e a vida na aldeia.

As perguntas continuaram, com a maioria das crianças parecendo bem interessada: "Como é que vocês fazem esses colares?"; "Como é o banheiro?"; "Como é a escola indígena?"; "O que o seu pai fazia quando você ainda morava na aldeia?”; “O que vocês fazem na aldeia?”. A essa última pergunta, ele respondeu que grande parte das brincadeiras das crianças na aldeia se dava nas águas do rio que passava na região. Em relação à pergunta seguinte - "Como vocês fazem brinquedo lá?" -, ele disse que diversos brinquedos também usados na cidade, como a peteca, e brincadeiras como a cama de gato e o cabo de guerra são "originalmente deles, indígenas".

A questão seguinte provocou uma longa digressão de Awá, levando-o a remontar a momentos de sua infância, assim como a trazer para a discussão uma visita que ele fez a outra escola no Rio de Janeiro. Fernando lhe perguntou: "Como você aprendeu a nadar?", suscitando a seguinte resposta:

Eu nunca tinha parado para pensar sobre isso - porque todos os Tembé sabiam nadar, e eu nunca tinha me perguntado sobre como a gente aprendia, porque era uma coisa táo comum... Até que uma criança de uma escola aqui do Rio me perguntou isso uma vez, e eu comecei a pensar sobre como eu tinha aprendido a nadar. Aí eu lembrei que, quando a gente ainda era bem novo, diziam para a gente que, para aprender a nadar, a gente tinha que comer umas piabinhas, mas tinha que comer elas vivas; engolir com um pouco de água. E a gente fazia isso, e acabava aprendendo a nadar. Mas depois é que eu vi que, para pegar as piabinhas, a gente tinha que se jogar na água, e de tanto que a gente se esforçava e se batia na água, acabava aprendendo a nadar! Então, foi assim que eu aprendi.

Se, antes, Awá tomava o nadar como um dado, ${ }^{11}$ esse questionamento o levou a repensar a forma pela qual os Tembé aprendem a nadar - a qual é também, em muitos aspectos, a forma pela qual um Tembé se torna um Tembé.

Em seguida, Awá deixou que Moisés Lopes falasse, e o apresentou, dizendo:

Agora eu vou passar a palavra aqui para o Moisés, que está aqui do meu lado. O Moisés tem se interessado aí pela nossa cultura, pelos índios, e está aí se aproximando da gente e aprendendo a nossa cultura, e ele também pode falar um pouco para vocês aqui... 
Moisés, "o jornalista que virou índio", contou um pouco do seu interesse pela causa indígena:

Eu me aproximei deles porque eu fui me envolvendo com a causa indígena. Não sei se isso diz muita coisa para vocês, mas eu vou explicar mais ou menos como isso aconteceu. Quando eu era pequeno, eu morei em um lugar chamado Jaconé [uma regiáo no interior do estado do Rio de Janeiro]. Jaconé é um nome indígena, e, quando eu estava lá com o meu pai, teve uma vez que eu pisei em um monte de conchas, e perguntei para o meu pai o que era aquilo. Ele me disse que aquilo eram coisas deixadas por uns índios que viviam ali. Lá, antigamente, viviam índios, mas eles foram expulsos de lá. Sabem por quê?

Paulo imediatamente levantou a mão e disse: "Eu sei! Foi o Cabral!”. A professora, a coordenadora e os visitantes deram um leve sorriso, imaginando que ele estava se referindo a Pedro Álvares Cabral, um dos primeiros portugueses a pisar nesse solo e a dar início à colonização portuguesa nas terras que viriam a se chamar Brasil. Tatiane olhou para ele, sorrindo, e perguntou: "Muito bem, Paulo! Mas que Cabral é esse?". Paulo respondeu, contrariado e com os punhos cerrados: "O Cabral, aquele governador metido, que expulsou os índios!". Tatiane, Manuela, eu e os dois visitantes rimos, pois só então percebemos que Paulo não estava falando de Pedro Álvares Cabral, mas sim de Sérgio Cabral, governador eleito do estado do Rio de Janeiro, que governou de 2006 a 2014. Em vários momentos ao longo do ano de 2013, o governo do estado coordenou uma série de ações, envolvendo o Batalhão de Choque da Polícia Militar, para expulsar os índios da Aldeia Maracaná, com a finalidade de desocupar o prédio do antigo Museu do Índio. A truculência dessas açóes ganhou repercussão na mídia, levando Paulo a associar [Sérgio] Cabral com a expulsão dos índios. Paulo não confundiu Sérgio Cabral com Pedro Álvares Cabral - afinal, ambos realmente representaram uma ameaça aos povos indígenas. De fato, a história se repetiu: primeiro como tragédia e, depois, não como farsa, mas como tragédia novamente.

As últimas perguntas a serem feitas foram pensadas pelas crianças a partir de uma discussão sobre higiene: "Como vocês tomam banho lá?"; "Lá tem shampoo?”; e a última pergunta: "Como vocês se secam lá? É igual a cachorro?". Awá riu e respondeu: "Não sei se é igual a cachorro, mas a gente deixa a água evaporar do corpo. A gente não tem o costume de secar com toalha”. 
Awá, então, convidou todos a se levantarem. Ele mostrou uma peteca, um coquinho e um chocalho para a turma e então os chamou para uma dança, na qual todos dançaram em roda, enquanto Awá cantava em sua língua nativa e segurava o chocalho. Após a dança, os convidados se despediram, enquanto a professora e a turma ficaram comentando sobre como a visita tinha sido "legal".

\section{Desdobramentos, ou um outro desencontro}

No dia 17 de março, na semana seguinte à visita, a professora Tatiane passou uma folha de autoavaliação, para que cada criança dissesse o que achou da visita de Awá Tembé e de Moisés Lopes. À exceção da última, as demais perguntas da folha eram de múltipla escolha, com questóes como "Você fez perguntas a eles?", "Você prestou atenção ao que eles diziam?". A penúltima pergunta era: "Você gostou da visita do Awá e do Moisés Lopes?", e a última, discursiva, com o espaço de uma linha para a resposta, era: "Por quê?".

Ao ver as folhas respondidas pela turma, percebi que onze dos doze alunos responderam que "sim" em relação a terem gostado da visita. As justificativas eram: "Porque eu aprendi muita coisa"; "Eles eram legais"; "Os índios eram simpáticos". Thiago, no entanto, respondeu que não gostou, e justificou dizendo: "Eu odeio índios".

Surpreso com a sinceridade - e a intensidade - dessa resposta, busquei levar a sério esse ódio, perguntando a ele:

- Thiago, por que você respondeu que não gosta de índios?

- Porque eu odeio índios! - respondeu, enfatizando o odeio.

- Mas por quê? - insisti.

- Porque, nos filmes que eu assisto, os índios sempre demoram a desaparecer. E aí é chato!

- Mas como assim?

- Eles demoram a desaparecer! Eles ficam o tempo todo aparecendo, aí cansa, fica chato!

- Mas nesses filmes os índios são do bem ou do mal? - perguntei, percebendo que ele possivelmente se identificaria com as noçóes substantivas de bem e mal praticadas por Hollywood.

- Do mal!

O índio, retratado como inimigo em filmes norte-americanos, passa de fato a ser encarado como inimigo por espectadores como Thiago. De repente, a notícia de que sua turma será visitada por um índio o assusta, fazendo com que ele fique calado durante todo o tempo do encontro. Posteriormente, com a autoavaliação passada pela professora, ele encontrou uma oportunidade para expressar seu ódio e sua insatisfação com esse encontro. 


\section{Ser humano, ser índio, ser criança}

Remontando à reuniáo de pais e professores narrada no início do texto, as principais questóes a serem debatidas com a visita de Awá Tembé e Moisés Lopes se referiam a uma discussão sobre individualidade, identificação e diferença, em torno de perguntas como: "Quem são os Manchineri de lá (da aldeia) e os Manchineri de cá (da sala de aula)?” e "Como vivem as crianças indígenas?”. Ao longo do encontro dos indígenas com os estudantes, essas perguntas foram se desdobrando em outras, a partir das quais as crianças se preocuparam principalmente em descobrir as diferenças entre elas e os visitantes, por meio de questóes que os definiam a partir de ausências: lá - na aldeia - não tem televisão, não tem teatro, não tem circo, não tem hospital, não tem cama, entre outros. Desse modo, ao descrevê-los a partir do que eles não têm, as crianças acabaram descrevendo a si próprias a partir de todas essas presenças: aqui - na cidade - tem televisão, teatro, cama etc. $\mathrm{Ou}$, em outras palavras, ao inventarem a cultura desses defensores da causa indígena, elas inventaram elementos de sua própria cultura (WAGNER, 2012, p. 43).

De diversas formas, esse encontro pareceu reafirmar algumas diferenças. Afinal, o que mais atraiu a atenção das crianças foi pensar em que aspectos eles são iguais ou não a nós. Em diversos momentos, a questão da humanidade dos visitantes foi trazida à tona, e náo só pelas crianças. $\mathrm{Na}$ reuniáo com os pais, Manuela aponta para o próprio corpo ao sugerir que Moisés Lopes era gente que, então, se transformou em indio. Esse tópico foi retomado pelas crianças, por meio de perguntas como "Vocês comem inseto e lesma?" e "Como vocês se secam lá? É igual a cachorro?".

No entanto, uma possibilidade muito interessante foi trazida pela presença de Moisés Lopes, na medida em que este se colocou ali como um ser humano intermediário entre o índio e o não índio. Afinal, como Manuela o definiu, ele é o jornalista carioca que se tornou índio - no entanto, em nenhum momento lhe foi reconhecida a possibilidade de ele ser tão indio quanto Awá. As limitaçóes do seu reconhecimento como índio foram também ressaltadas por Tatiane, que, ao apresentar os visitantes à turma, disse: "Um, eu acho que é índio, que nasceu na tribo mesmo. O outro nasceu aqui, mas foi viver na tribo com os índios": portanto, nascer na tribo parece ser um fator essencial para que ele seja de fato considerado um índio.

Awá apresentou Moisés para a turma como sendo alguém que "tem se interessado aí pela nossa cultura, pelos índios, e está aí se aproximando da gente e aprendendo a nossa cultura”. Em suas próprias palavras, por sua vez, Moisés se definiu como alguém que se aproximou dos índios porque foi se envolvendo com a causa indígena. As crianças, por outro lado, o con- 
sideraram logo de imediato como sendo "o índio da cidade". Desse modo, a percepção desse lugar intermediário e fluido ocupado por ele entre ser da aldeia e ser da cidade fez com que ele trouxesse à tona a possibilidade de transformação, de mudança de identidade - aproximando, assim, os indígenas visitantes às crianças da turma. Se, em alguns aspectos, a discussão sobre identidade se aproximou de uma discussão sobre humanidade - registrada em falas da professora e da coordenadora, assim como em perguntas das crianças -, por outro lado, a presença de Moisés como um ser intermediário entre índios e não índios parece ter servido de elemento para se pensar uma comum humanidade entre as crianças e os índios. Assim, grosso modo, Moisés foi uma espécie de mediador, evitando com que algo parecido com um relativismo cultural fosse compreendido pelas crianças como uma espécie de relativismo natural: ${ }^{12}$ depois de reconhecidas algumas diferenças, presenças e ausências entre índios e não índios, parece ter havido um consenso quanto a uma humanidade compartilhada por ambos.

Outro aspecto curioso a ser rapidamente discutido aqui é o fato de que, se, nessa sala de aula, o contato entre índios e crianças se deu como um encontro, em termos de teoria antropológica, poderíamos pensá-lo como um reencontro - levando em consideração as relaçóes feitas por muitos dos primeiros pensadores da antropologia entre a infância e a cultura primitiva (como discutido em FIANS, 2015, p. 19-24). Em seu estudo sobre a cultura primitiva (1920), Edward B. Tylor, por exemplo, trata da progressão da cultura de seu estágio selvagem até o civilizado, comparando a condição moral e intelectual dos selvagens a das crianças (1920, p. 31). Propondo uma noção de cultura que consiste em um todo e que inclui elementos como conhecimentos, crenças e costumes, ele defende que as crianças podem ser relacionadas à infância da civilizaçáo humana, o que, de acordo com ele, pode ser percebido pela ideia de que "o que é feito entre os homens civilizados em tom de brincadeira, ou entre as crianças civilizadas no berçário, tende a encontrar seu análogo no esforço mental sério do selvagem, e, portanto, das tribos primitivas" (1920, p. 180, tradução minha). Como ressaltado por Charlotte Hardman (2001, p. 502, 505-508), Herbert Spencer também relaciona crianças e selvagens, mas com algumas ressalvas, dizendo, por exemplo, que, apesar de a criança atribuir personalidade aos bonecos e falar e brincar com eles como se eles estivessem vivos, ela não acredita realmente que eles sejam seres vivos, mas apenas se utiliza de uma ficção deliberada.

Atualmente, depois de essas teorias antropológicas terem sido revisitadas, e para além desse contato com o outro que nos informa sobre nós mesmos, fazendo com que todos sejamos de fato antropólogos - dessa intersubjetividade a partir da qual produzimos significados para o mundo 
e suas relaçóes (TOREN, 1999, p. 18; 2013, p. 173) -, há ainda outro aspecto a ser ressaltado. Se fôssemos manter os chamados grandes divisores (GOLDMAN; LIMA, 1999) - o que não busco fazer aqui -, seríamos levados a pensar essa visita náo só como um encontro entre indios e brancos, mas principalmente entre adultos indígenas e crianças brancas. Assim como partilhas como indios e brancos ou primitivos e civilizados já levaram a antropologia por caminhos obscuros, o mesmo se deu em relaçáo à demarcação entre adultos e crianças. Esse grande divisor etário, se assim podemos chamá-lo, é reforçado em obras de referência na sociologia e na antropologia da criança e da infância, por meio de autores como William Corsaro.

Ao enfatizar uma distinção radical entre as culturas infantis de pares e as culturas adultas, Corsaro $(2002 ; 2003)$ não atenta, por exemplo, para a existência de crianças e adultos de diferentes idades, assim como de adolescentes e jovens - além de opor radicalmente as experiências e relaçóes estabelecidas de acordo com a faixa etária dos atores. Essa distinçáo parece ser reforçada pelo ambiente escolar, o qual tende a diferenciar quem é criança/estudante, por um lado, e quem é professor, funcionário, pai ou mãe/adulto, por outro. ${ }^{13}$ Insistir nessa oposição entre o adulto detentor e transmissor de conhecimentos e a criança receptora de conhecimentos e de cultura seria remontar às aproximaçóes entre crianças e selvagens, na medida em que a capacidade cognitiva delas passa a ser vista como limitada, como algo fofo ou divertido, em vias de alcançar o amadurecimento que caracterizaria a idade adulta.

Portanto, ao mesmo tempo que crianças e índios - enquanto atores concretos - se aproximam em uma sala de aula, crianças e índios - enquanto seres e conceitos abstratos - já há tempos foram aproximados por antropólogos, sociólogos e outros pensadores.

\section{Quando a sala de aula se torna uma varanda}

De volta à discussão sobre métodos de pesquisa etnográfica, outro ponto importante a ser considerado é que, na antropologia de varanda, os indígenas que são chamados a depor perante os brancos sobre seu povo e seus valores são tidos como representantes de suas aldeias, na medida em que apresentam a vida de seu povo e respondem em nome de seu grupo ou aldeia. No entanto, nessa antropologia de varanda manifestada como antropologia de sala de aula, essa relação metonímica de substituição da parte - um ou dois indígenas - pelo todo - uma aldeia - é ainda mais intensa e radical: as crianças, e até mesmo a professora e a coordenadora, não os viram como representantes dos índios Tembé, ou dos ex-moradores da Aldeia Maracaná, mas sim como representantes dos indígenas, considerados 
de uma forma mais ampla. Desse modo, eles estavam ali falando não só em nome de uma determinada etnia, tomando esta como uma totalidade, mas também de toda a categoria índio. Será que, com esse tipo de generalização proporcionada por essa relação metonímica, há o risco de se banalizar e se exotizar aspectos das vidas e dos costumes dos diversos povos indígenas brasileiros (TASSINARI; GOBBI, 2009, p. 109)? Mas como seria possível proceder de outra maneira?

Izabel Gobbi (2007) relata um projeto de extensão, coordenado pela Universidade Federal de Santa Catarina (UFSC), que tinha por objetivo promover um intercâmbio interescolar entre crianças guarani e crianças não indígenas de duas escolas em Santa Catarina - no qual as crianças de uma escola iam visitar as de outra. Antes da realização desse encontro, foram feitas reunióes para que tanto crianças quanto professoras debatessem as expectativas e os preparativos e, nos dias em que esses encontros se realizaram, tanto as crianças náo indígenas foram à escola Guarani quanto as crianças Guarani foram à escola não indígena. ${ }^{14}$ No entanto, até que ponto podemos afirmar que as crianças náo indígenas perceberam as demais como Guarani, e não como crianças indígenas, de uma maneira igualmente genérica? Tantos as Guarani quanto as não indígenas saíram da varanda e foram para o campo, na medida em que uma turma visitou a escola da outra. Mas até que ponto é possível afirmar que um grupo não criou uma imagem estereotipada do outro?

Apesar das limitaçóes e do constante risco de superficialidade que esse tipo de encontro pode trazer, o contato entre atores concretos parece proporcionar um diálogo proveitoso e algumas reflexôes sobre questóes relacionadas a identidade, diferença e modos de estar no mundo - como demonstrei por algumas das falas e das perguntas feitas pelas crianças.

Por outro lado, o que pensar da perspectiva dos índios sobre esse encontro? Do ponto de vista dos visitantes, a antropologia reversa (WAGNER, 2012, p. 98-106) esteve próxima de alcançar o auge de sua reversibilidade, a partir das reflexóes sobre os indígenas e sobre as crianças da escola provocadas por esse encontro. A varanda - hoje substituída por um ambiente fechado, climatizado, e iluminado não por luz natural, mas por lâmpadas - se revela o lugar perfeito para uma observação participante por parte dos indígenas. Ao mesmo tempo que as crianças estavam formulando uma imagem dos índios a partir da narração das experiências de Awá e de Moisés, estes também estavam inventando uma imagem das crianças e de si mesmos, ao questionarem alguns dos pressupostos básicos de suas culturas e histórias.

Como somos todos antropólogos, assim como somos também todos nativos, Awá e Moisés não estavam ali apenas sendo observados, analisa- 
dos e julgados, mas também fazendo uma etnografia desse encontro com as crianças brancas de classe média de Vila Isabel. Como citado antes, foi em uma visita feita previamente a outra escola que Awá parou para pensar mais detidamente sobre como ele tinha aprendido a nadar; e, durante o encontro que narrei, Moisés remontou ao seu passado e parecia preocupado em dar um panorama sobre sua infância em Jaconé para então explicar às crianças seu interesse pela causa indígena. Assim, esse contato não só informa as crianças como também provoca reflexôes a partir dessas narraçóes de experiências.

Ainda como apresentado por Roy Wagner (2011), a antropologia reversa contempla também o fato de que uma nova relação é possível: aquela na qual os indígenas se apresentam como professores, e os brancos - tanto crianças quanto adultos, no caso narrado -, como alunos. Ou, nos termos de Wagner, ao se referir a uma experiência própria, "nossos pretensos objetos de estudo estáo nos ensinando" (2011, p. 969): as crianças fazem perguntas e, de forma criativa, reinventam sua cultura a partir da cultura que os indígenas lhes transmitiram; mas é igualmente importante o fato de que os dois indígenas também estáo empenhados em construir essa ponte que lhes permite conhecer o Outro e a si próprios, e, dessa forma, inventarem suas culturas e histórias - assim como as próprias noçóes de cultura e história. Além disso, os indígenas mostraram ainda às crianças outra forma de aprender: pela dança - que foi a maneira como eles encerraram o encontro: cantando, apresentando seus instrumentos e sua língua pela música e pela performance corporal.

Moisés Lopes, por sua vez, ocupa um lugar-limite nesse processo, olhando a cultura de Awá e a cultura das crianças da escola na qual ele estudou como espaços pelos quais ele pode transitar de forma criativa. E esse trânsito, de alguma maneira, se realiza, na medida em que Moisés é ele mesmo classificado de diversas maneiras a cada momento - como índio da cidade, como jornalista, como ex-aluno daquela escola e como membro atuante na defesa da causa indígena - e ele próprio também se utiliza dessas classificaçóes para se aproximar das crianças sem, ao mesmo tempo, se distanciar dos movimentos indígenas.

Ao final da visita, em uma conversa pessoal, Awá me falou ainda sobre como é importante para ele fazer essas apresentaçóes em escolas, a fim de conscientizar as crianças sobre o que acontece com os índios no Brasil, bem como passar para elas algumas noçóes sobre a vida e os valores mantidos pelos grupos indígenas.

Assim, Awá e Moisés não estavam ali apenas falando passivamente sobre "seu povo e sua cultura": eles estavam aprendendo e ressignificando a partir de suas próprias falas e do encontro deles com as crianças - ou seja, 
intersubjetivamente. Se, tal como narrada, essa antropologia de varanda em uma sala de aula não consiste em uma via de máo única - em termos de aprendizados e transmissóes de conhecimentos -, certamente a antropologia de varanda que marcou a história da disciplina também consistia em uma oportunidade para que os selvagens produzissem significados para os antropólogos e demais atores presentes naqueles encontros.

Talvez, afinal, eu não fosse a única pessoa ali naquela sala de aula a fazer uma observaçáo participante e a carregar um caderno de campo na mochila - com a diferença de que eu e os índios estávamos no campo, etnografando crianças, enquanto estas compreendiam os Outros a partir de um local já frequentado por elas: da escola, um lugar criado para elas; de sua varanda.

\section{Notas}

1. O presente trabalho foi realizado durante meu mestrado em Antropologia Social no Museu Nacional, Universidade Federal do Rio de Janeiro (PPGAS-MN-UFRJ), com apoio da Capes (Coordenação de Aperfeiçoamento de Pessoal de Ensino Superior - Brasil). Uma versão anterior deste texto foi apresentada no Seminário Interno dos Alunos do PPGAS-MN-UFRJ. Agradeço a Marcio Goldman e a Edgar Rodrigues Barbosa Neto pelo apoio e pelos comentários feitos à versão anterior. Agradeço também a Flávia Pires, a Luciana Hartmann e a Guilherme Sá pelas trocas de ideias sobre antropologia e sobre pesquisas com crianças.

2. A ideia de sair da varanda para fazer um trabalho de campo é também apresentada no documentário Bronislaw Malinowski: Off the Verandah, escrito e dirigido por André Singer e Bruce Dakowski (1986).

3. Para a realização dessa pesquisa, obtive a autorização do diretor da escola, assim como informei a todos os envolvidos - coordenadores, funcionários, professores, pais e alunos das turmas - sobre a minha presença enquanto pesquisador. $\mathrm{O}$ diretor assinou uma autorizaçáo para a pesquisa, me permitindo também identificar a escola nas publicaçôes decorrentes desse trabalho de campo. Todos os responsáveis pelas crianças envolvidas também assinaram termos de consentimento.

4. Informaçôes obtidas no endereço eletrônico: <http://www.ogamita.com. $\mathrm{br} />$. Acesso em novembro de 2014.

5. Para esta pesquisa, me utilizo da observaçáo do encontro da turma da tarde, que foi a que acompanhei ao longo de meu trabalho de campo.

6. Nos termos de consentimento e de autorização para a pesquisa, assinados por mim, pelo diretor da escola e pelos pais, me proponho a não utilizar os nomes reais dos atores do campo. A fim de preservar os nomes dos 
envolvidos, uso nomes fictícios para me referir à turma, aos funcionários e aos alunos. Pelo mesmo motivo, também formulei nomes fictícios para os defensores da causa indígena que visitaram a escola nessa ocasiáo aqui relatada. Para a escolha da etnia que dá nome à turma, Manchineri, assim como da etnia de um dos visitantes, Tembé, substituí os nomes reais da turma e da etnia pelo de povos indígenas que tivessem aspectos em comum com os do trabalho de campo, tomando como principais critérios para isso similaridades quanto à família linguística e localização dos povos.

7. Juliana estava se referindo a Tonico Benites [nome real], que havia acabado de concluir seu doutorado em Antropologia Social no PPGAS-MN-UFRJ.

8. Um dos pais presentes disse ter pensado que, por eu ser antropólogo, eu estava buscando comparar as crianças da cidade com as crianças indígenas, embora minha intenção fosse apenas a de fazer uma etnografia naquela escola.

9. Ainda sobre a minha presença enquanto antropólogo, uma das mães disse: "Eu também sou antropóloga! Então, agora eu vou te passar a missão de explicar para a minha filha o que um antropólogo faz, porque até agora eu não consegui fazer com que ela entendesse isso!”.

10. Por uma questão de espaço, apresentarei apenas algumas das respostas dadas às perguntas feitas pelas crianças.

11. Para uma breve discussão sobre a noção de taken for granted - frequentemente traduzida como tomar como dado -, ver Toren (1999, p. 13-14).

12. Eduardo Viveiros de Castro sugere o termo multinaturalismo para se referir à ideia de que as cosmologias ameríndias supóem a existência de uma só "cultura" e de múltiplas "naturezas" - dessa forma, os ameríndios seriam multinaturalistas, e não multiculturalistas (2013, Capítulo 7). Ao me referir a relativismo natural, no entanto, não me refiro a essa noção, pois a discussão suscitada nessa sala de aula sobre semelhanças e diferenças entre os atores engloba, a princípio, tanto a possibilidade de múltiplas culturas quanto de múltiplas naturezas - não sendo, portanto, apenas um multinaturalismo. A multiplicidade de naturezas depois é reconsiderada graças à mediação de Moisés, que mostra que é possível passar de "não índio" para "índio".

13. Em alguns casos, os estagiários podem ser vistos como mediadores, na medida em que muitos deles são associados à figura do professor, mas, ao mesmo tempo, costumam ter mais abertura para interagir diretamente e brincar com as crianças.

14. Como Izabel Gobbi trabalhava no referido projeto de extensão e este era coordenado por uma antropóloga, ela pôde acompanhar os desdobramentos desses encontros e as percepçóes das crianças sobre eles. No meu caso, no entanto, eu estava na escola apenas fazendo uma observação participante, de modo que não me foi possível intervir diretamente no planejamento 
das aulas e dos conteúdos a serem transmitidos - planejamento o qual é feito pela professora. Se tivesse sido possível, teria sido interessante retomar esse encontro com as crianças em uma aula seguinte, de modo a discutir as percepçôes delas sobre os visitantes indígenas. No entanto, a única medida tomada pela professora para debater isso posteriormente foi a formulação do já referido questionário, baseado principalmente em questôes de múltipla escolha.

\section{Referências bibliográficas}

BRASIL; MEC. Parâmetros Curriculares Nacionais: pluralidade cultural, orientação sexual. Secretaria de Educação Fundamental. Brasília: MEC/SEF, 1997.

BRASIL. Lei Ordinária (1996). Lei de Diretrizes e Bases da Educação. Diário Oficial da União. Brasília, DF, 23 de dezembro de 1996. Disponível em: $<$ http://portal.mec.gov.br/secad/arquivos/pdf/ldb.pdf>. Acesso em $15 \mathrm{de}$ agosto de 2014.

CLASTRES, Pierre. A sociedade contra o Estado: investigaçóes de antropologia política. Porto: Ediçôes Afrontamento, 1979.

CORSARO, William. A reprodução interpretativa no brincar ao "faz de conta" das crianças. Educação, Sociedade e Culturas, n. 17. 2002.

"We're friends, right?": Inside kid's culture. Wasington: Joseph Henry Press, 2003.

FIANS, Guilherme. Entre crianças, personagens e monstros: uma etnografia de brincadeiras infantis. Rio de Janeiro: Ponteio Ediçôes, 2015.

GOBBI, Izabel. A diversidade cultural vivenciada na infância: um intercâmbio entre crianças Guarani e crianças não-índias. Seminário Temático 14 Do ponto de vista das crianças: pesquisas recentes em Ciências Sociais. $31^{\circ}$ Encontro Anual da Anpocs, Caxambu, 2007. Disponível em: <http://www. anpocs.org/portal/index.php?option=com_docman\&task =doc_view\&gi$\mathrm{d}=2898$ \&Itemid=231 $>$. Acesso em 2 de setembro de 2015.

GOLDMAN, Marcio; LIMA, Tania Stolze. Como se faz um grande divisor? In: GOLDMAN, Marcio. Alguma antropologia. Rio de Janeiro: Relume-Dumará, 1999.

HARDMAN, Charlotte. Can There Be an Anthropology of Children? Childhood, v. 8, n. 4. 2001.

MALINOWSKI, Bronislaw. Argonautas do Pacifico Ocidental. Um relato do empreendimento e da aventura dos nativos nos arquipélagos da Nova Guiné melanésia. Coleção os Pensadores. São Paulo: Abril Cultural, 1976.

TASSINARI, Antonella Maria Imperatriz; GOBBI, Izabel. Políticas públicas e educação para indígenas e sobre indígenas. Educação, v. 34, n.1. 2009.

TOREN, Christina. Mind, Materiality and History: explorations in Fijian ethnography. Londres/Nova York: Routledge, 1999. 
. Uma Antropologia além da Cultura e da Sociedade: Entrevista com Christina Toren. Entrevista concedida a Guilherme Fians. Revista Habitus, v. 11, n. 1.2013.

TYLOR, Edward B. Primitive Culture - Vol.1. London: John Murray, 1920.

VIVEIROS DE CASTRO, Eduardo. A inconstância da alma selvagem e outros ensaios de antropologia. São Paulo: Cosac Naify, 2013.

WAGNER, Roy. "O Apache era o meu reverso": entrevista com Roy Wagner. Entrevista concedida a Florencia Ferrari, Iracema Dulley, Jamille Pinheiro, Luísa Valentini, Renato Sztutman e Stelio Marras. Revista de Antropologia (USP), v. 54, n. 2. 2011.

. A Invenção da Cultura. São Paulo: Cosac Naify, 2012.

\section{Autor Guilherme Fians}

Mestre em Antropologia Social pelo Museu Nacional, Universidade Federal do Rio de Janeiro, e Doutorando em Antropologia Social pela University of Manchester.

Artigo recebido em: 23/04/2015 Artigo aprovado em: 08/03/2016 